\section{National Wind Technology Center to Debut New Dynamometer}

Highlights in

Research \& Development
New test facility will be used to accelerate the development and deployment of next-generation wind energy technologies.

This fall, the National Wind Technology Center (NWTC) at the National Renewable Energy Laboratory (NREL) will open a new dynamometer test facility. Funded by a grant from the U.S. Department of Energy under the American Recovery and Reinvestment Act (ARRA), the new facility will offer wind industry engineers a unique opportunity to conduct a wide range of tests on the mechanical and electrical power producing systems of a wind turbine including generators, gearboxes, power converters, bearings, brakes, lubrication, cooling, and control systems.

Dynamometers enable industry and testing agencies to verify the performance and reliability of wind turbine drivetrain prototypes and commercial machines before they are deployed in the field, thus reducing the risk of possible failures and maintenance or replacement costs. The drivetrains are tested by simulating operating field conditions in a laboratory environment. In a typical dynamometer test, a powerful motor replaces the rotor and blades of a wind turbine.

As one of the largest dynamometers in the world, the new NWTC facility will be capable of testing the performance of wind turbine drivetrains with capacity ratings up to 5 megawatts. The new facility incorporates a hydraulic device that simulates all the forces and moments that a wind turbine rotor imparts on a drivetrain in addition to torque. Only a handful of test facilities in the world have this capability; drivetrain testing under torque loads only is the norm.

In addition to testing the performance of multi-megawatt drivetrains, a drivetrain under test at the new NWTC facility can also be connected either directly to the grid or to a Controllable Grid Interface (CGI) to provide system engineers with a better understanding of how wind turbines react to grid disturbances. The CGI will test wind turbines offline from the grid, verify compliance with standards, and provide grid operators with the performance information they need for a fraction of the time and cost it would take to test the turbine in the field.

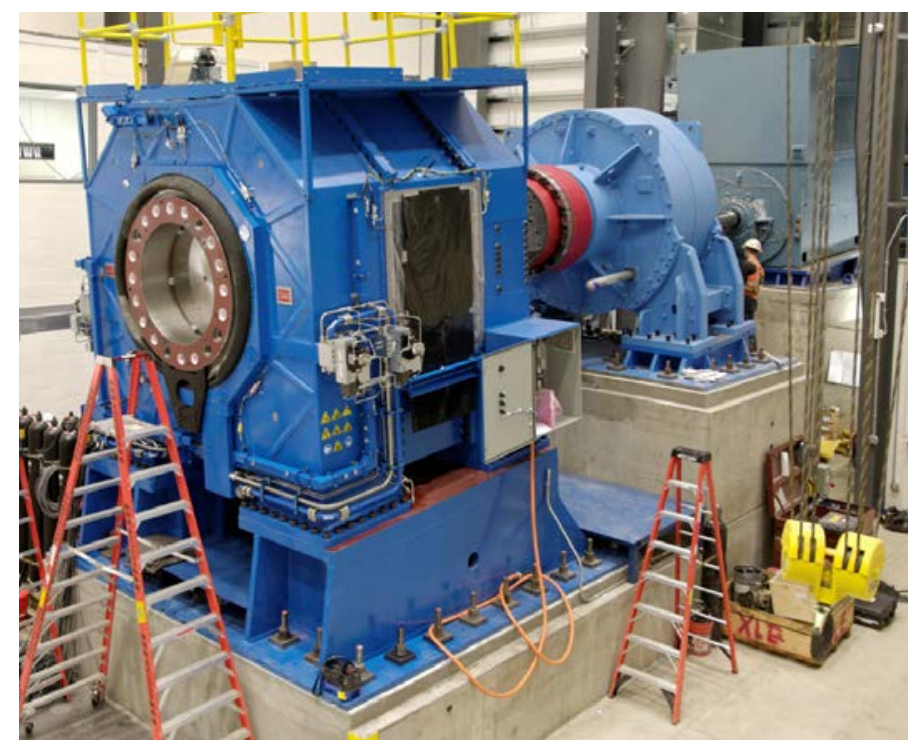

New dynamometer test facility under construction at the NWTC. Photo by Mark MCDade, NREL 24472

\section{Key Research Results}

\section{Achievement}

With funding from an ARRA grant from the Energy Department, NREL's National Wind Technology Center will open a new dynamometer test facility this fall.

\section{Key Result}

The new facility will offer wind industry engineers a unique opportunity to conduct a wide range of tests on the mechanical and electrical power producing systems of wind turbines.

\section{Potential Impact}

Research conducted at the new facility will accelerate the development and deployment of next-generation wind energy technologies.

Technical Contact: Mark McDade, mark.mcdade@nrel.gov
NREL is a national laboratory of the U.S. Department of Energy, Office of Energy Efficiency and Renewable Energy, operated by the Alliance for Sustainable Energy, LLC.

15013 Denver West Parkway Golden, CO 80401 303-275-3000 | www.nrel.gov 